\title{
Metastatic prostate cancer with malignant ascites: A case report and literature review
}

\author{
Ifeanyi Ani, MD; ${ }^{*}$ Mark Costaldi, $M D ;{ }^{\dagger}$ Robert Abouassaly, $M D^{*}$ \\ *Department of Urology, University Hospitals Case Medical Center, Cleveland, $\mathrm{OH}$; 'Department of Pathology, University Hospitals Case Medical Center, Cleveland, $\mathrm{OH}$
}

Cite as: Can Urol Assoc J 2013;7:E248-50. hittp://dx.doi.org/10.5489/cuai.547

\section{Abstract}

Malignant ascites from advanced prostate cancer is rare and has a poor prognosis. We report a case of a 57-year-old African American male presenting with weight loss, lower urinary tract symptoms and voiding dysfunction. He also had renal failure with metabolic abnormalities associated with significant abdominal distention and pain. Computed tomography showed ascites, which was pathologically confirmed by immunostaining and cytological identification of malignant cells. Prostate biopsy identified high-grade prostate cancer which responded to hormonal therapy with a significant decrease in serum prostatic-specific antigen. Ascites was managed with paracentesis and renal failure with hemodialysis as needed.

\section{Introduction}

Prostate cancer is the most common cancer in men and the second leading cause of death in men in the United States. ${ }^{1}$ It is estimated that about 240890 new diagnoses and 33720 deaths will result from prostate cancer in $2011 .^{1}$ It affects African American men (at an incidence rate of 234 cases per 100000 men) more than Caucasian men (150 cases per 100000 men). Most cases present with localized disease and have good prognosis. However, advanced metastatic prostate cancer commonly metastasizes to regional lymph nodes and vertebral bones, but metastasis to the peritoneum leading to malignant ascites is rare. There are only 15 published cases (Table 1). ${ }^{2-15}$ We report a case of malignant ascites from advanced metastatic prostate cancer with high volume disease in an African American male.

\section{Case report}

A 57-year-old African American male was admitted with fatigue, a 30-lb unintentional weight loss over 6 months, lower urinary symptoms, bilateral lower extremity edema and no gross neurological deficit. Initial potassium was $7.5 \mathrm{meq} / \mathrm{L}$ and blood urea nitrogen (BUN)-to-creatinine ratio of $46: 26 \mathrm{mg} / \mathrm{dL}$. A computed tomography (CT) of the abdomen and pelvis without contrast showed massive abdominal ascites, moderate bilateral hydronephrosis, right external iliac lymphadenopathy and enlarged prostate. Malignancy workup was negative except for a prostate-specific antigen (PSA) of $330 \mathrm{ng} / \mathrm{mL}$. He subsequently underwent transrectal ultrasound guided prostate biopsy, which demonstrated Gleason score $5+4=9$ in $80 \%$ of the biopsy bilaterally (Fig. 1). A bone scan showed osseous metastatic bone lesions in the T7 vertebral body, left fourth rib posteriorly and right proximal humerus. Therapeutic and diagnostic paracentesis was performed. A hazy yellow fluid was sent for analysis. The ascites fluid demonstrated malignant cells that immunostained with cytokeratin AE1/AE3, CAM 5.2, CK7, and prostatic acid phosphatase (PRAP) (Fig. 2). Ascites fluid creatinine was consistent with serum.

Bicalutamide, an antiandrogen, was used for androgen blockade for 2 weeks and initiated 7 days prior to starting a luteinizing hormone-releasing hormone (LHRH) agonist, to prevent testosterone flare associated with LHRH agonist therapy.

He was dialyzed for hyperkalemia and uremia and bilateral percutaneous nephrostomy tubes were placed for the obstructive uropathy. His creatinine and BUN ratio improved to $8.51: 31 \mathrm{mg} / \mathrm{dL}$ and his potassium normalized. He was discharged for follow-up with nephrology.

On follow-up, androgen depravation therapy with $\mathrm{LHRH}$ agonist resulted in a PSA decrease from over 300 to $40 \mathrm{ng} / \mathrm{mL}$ within 3 months. However, he remained symptomatic from the ascites with multiple hospital admissions for abdominal pain, nausea and vomiting, necessitating therapeutic paracentesis.

\section{Discussion}

The PSA era has lead to a stage and grade migration of prostate cancer with $60 \%$ to $75 \%$ of newly diagnosed prostate 


\begin{tabular}{|c|c|c|c|}
\hline Author & Age & Isolated ascites & Treatment \\
\hline Biegel et al. ${ }^{2}$ & 29 & No & None \\
\hline Rapoport et al. ${ }^{3}$ & 45 & No & Orchiectomy \\
\hline Megalli et al. ${ }^{4}$ & 58 & Yes & Diethylstilbestrol \\
\hline Appalaneni et al. ${ }^{5}$ & 60 & No & None \\
\hline Catton et al. ${ }^{6}$ & 63 & No & None \\
\hline Benedict et al. ${ }^{7}$ & 67 & Yes & Docetaxel + steroid \\
\hline Tsai et al. ${ }^{8}$ & 68 & No & Interferone \\
\hline Saif et al. ${ }^{9}$ & 70 & Yes & Thalidomide \\
\hline Maddan et al..$^{10}$ & 75 & No & Diethylstilbestrol \\
\hline Kehinde et al. ${ }^{11}$ & 76 & No & Orchiectomy \\
\hline Rapoport et al. ${ }^{3}$ & 76 & No & 5-FU + IP thiotepa \\
\hline Disdier et al. ${ }^{12}$ & 78 & No & Nilutamide \\
\hline Lapoile et al. ${ }^{13}$ & 80 & No & None \\
\hline Amin et al. ${ }^{14}$ & 83 & No & Hormonal withdrawl \\
\hline Zagouri et al. ${ }^{15}$ & 75 & Yes & Docetaxel \\
\hline
\end{tabular}

cancer presenting with low-stage disease (T1c). ${ }^{16-19}$ Most cases presenting with malignant ascites are associated with other metastatic sites, including bone, lymph nodes, omentum, rectal wall, liver, adrenal and pleural effusions. ${ }^{20}$ Physicians should be aware of the rare manifestation of advanced prostate cancer with ascites and the diagnostic tools to confirm the diagnosis. Ascites fluid can be character- ized using various immunostains (Fig. 2). This is particularly helpful in cases of high-grade, poorly differentiated prostate cancers that do not stain for PSA.

Therapy focuses on supportive care with paracentesis to alleviate abdominal pain and respiratory distress. Oncologically, treatment focuses on palliation with endocrine therapies (medical or surgical) and palliative chemotherapy. These therapies may add additional months to the life of patients; however, prognosis is poor with most dying in weeks to months.

\section{Conclusion}

Malignant ascites in prostate cancer is a poor prognostic sign. Clinicians should be aware that supportive and palliative care is currently the mainstay of treatment.

Competing interests: None declared.

This paper has been peer-reviewed.

\section{References}

1. Howlader N, Noone AM, Krapcho M, et al. SEER Cancer Statistics Review, 1975-2008, National Cancer Institute. Bethesda, MD, http://seer.cancer.gov/csr/1975_2008/. Accessed March 28, 2013.
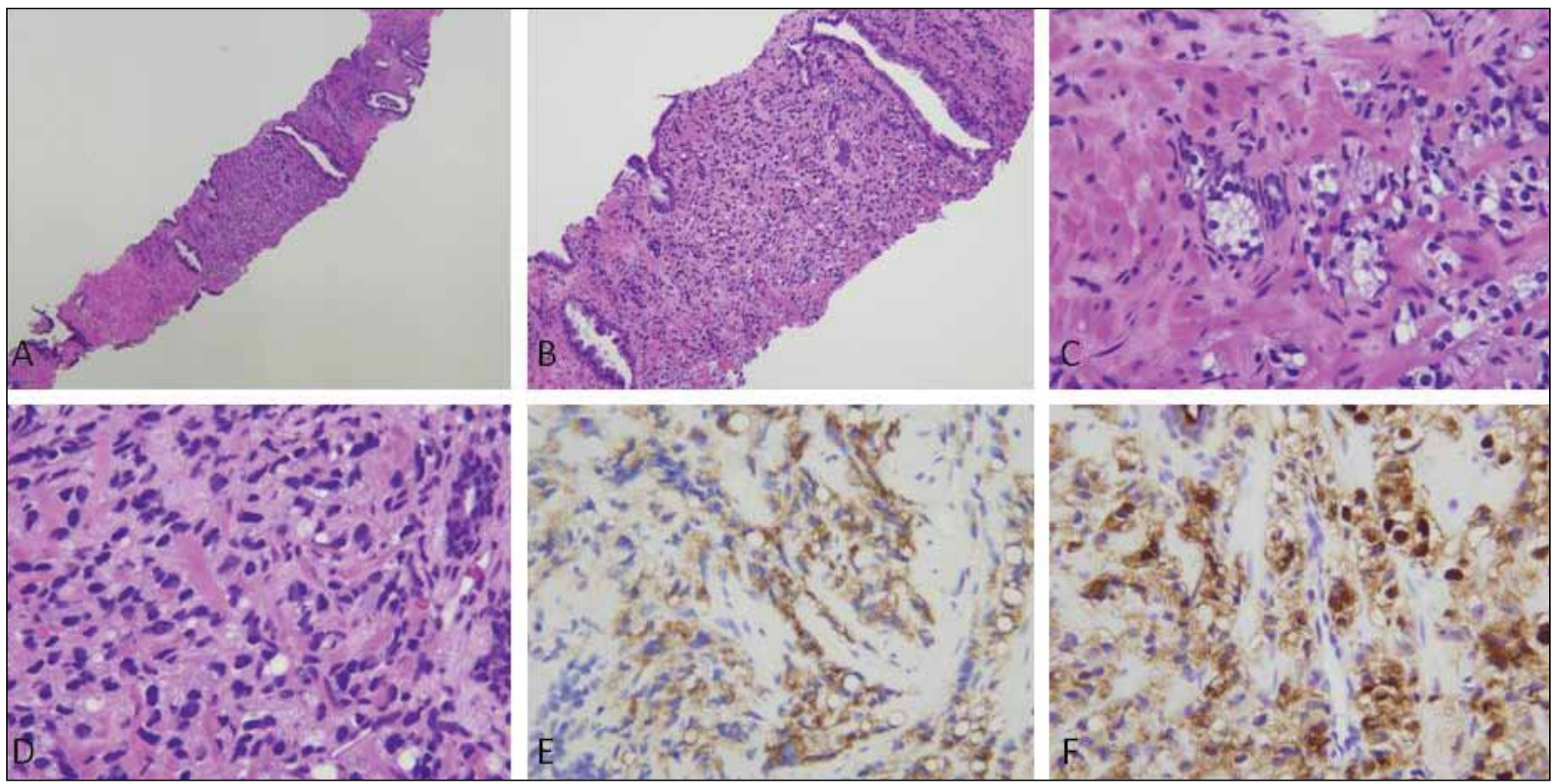

Fig. 1. A: Needle core biopsy of the prostate with $80 \%$ involvement by prostatic adenocarcinoma, Gleason $5+4=9$. B: Medium power view of the prostatic adenocarcinoma. C: Adenocarcinoma of the prostate, Gleason pattern 4. D: Adenocarcinoma of the prostate, Gleason pattern 5. E: Prostate-specific antigen immunostaining of prostatic adenocarcinoma cells. F: Prostatic acid phosphatase immunostaining of prostatic adenocarcinoma cells. 


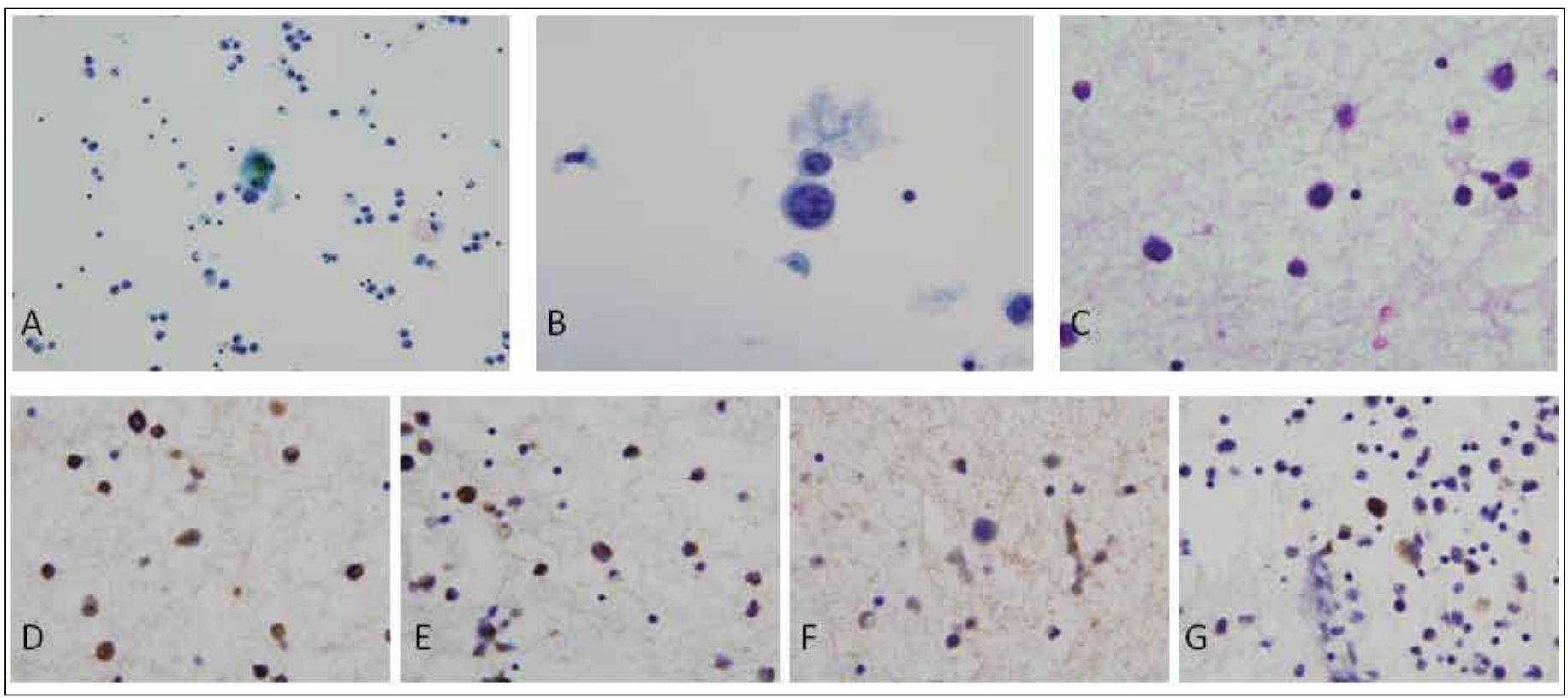

Fig. 2. Malignant ascites in a 57-year-old male with prostate adenocarcinoma. A: Low power overview of individual malignant cells and mesothelial cells in ascetic fluid (ThinPrep). B: Malignant cells derived from prostate adenocarcinoma demonstrating large nuclei with multiple nucleoli (ThinPrep). C: Malignant cells (Cell Block). Prostate adenocarcinoma cells highlighted in a cell block preparation by immunostaining for: D: AE1/AE3; E: CAM5.2; F: CK7; G: Prostatic acid phosphatase.

2. Beigel Y, Zelikouski A, Shimoni S, et al. Chylous ascites as a presenting sign of prostatic adenocarcinoma. Lymphology 1990;23:183-6.

3. Rapoport AH, Omenn GS. Dermatomyositis and malignant effusions rare manifestations of carcinoma of the prostate. J Urol 1968;100:183-7.

4. Megalli MR, Gursel E0, Veenema RJ. Ascites as an unusual presentation of carcinoma of the prostate. J Urol 1973; 110:232-4.

5. Appalaneni V, Yellinedi S, Baumann MA. Diagnosis of malignant ascites in prostate cancer by measurement of prostate specific antigen. Am J Med Sci 2004;327:262-3. http://dx.doi.org/10.1097/00000441200405000-00024

6. Catton PA, Hartwick RW, Srigley JR. Prostate cancer presenting with malignant ascites signet-ring cell variant of prostatic adenocarcinoma. Urology 1992;39:495-7. http://dx.doi.org/10.1016/00904295(92) 90259-Y

7. Benedict SP, Ahuja M, Mammen KJ. Hormone refractory carcinoma prostate with peritoneal metastases and malignant ascites without skeletal involvement: A case report and review of literature. Indian J Urol 2010;26:287-8. http://10.4103/0970-1591.65405

8. Tsai JY, Ling $M$, Chang VT, et al. Hemorrhagic ascites an unusual manifestation of prostate carcinoma. Am J Med 2001;111:245-6. http://dx.doi.org/10.1016/S0002-9343(01)00779-3

9. Saif MW, Figg WD, Hewitt $S$, et al. Malignant ascites as only manifestation of metastatic prostate cancer. Prostate Cancer Prostatic Dis 1999;2:290-3. http://dx.doi.org/10.1038/si.pcan.4500385

10. Madaan S, Palit V, Gudgeon P, et al. Omental metastasis with malignant ascites: an unusual manifestation of prostatic adenocarcinoma. Can Urol Assoc J 2007; 1:288-90.

11. Kehinde EO, Abdeen SM, A-Hunayan A, et al. Prostate cancer metastatic to the omentum. Scand I Urol Nephrol 2002;36:225-7. http://dx.doi.org/10.1080/003655902320131938
12. Disdier $P$, Harle JR, Swiader $L$, et al. Prostate carcinoma revealed by ascites with cachexia. Presse Medicale 1990;19:220

13. Lapoile E, Bellaïche G, Choudat L, et al. Ascites associated with prostate cancer metastases: an unusual localisation [in French]. Gastroenterol Clin Biol 2004;28:92-4.

14. Amin R. Chylous ascites from prostatic adenocarcinoma. Urology 2002;59:773. http://dx.doi. org/10.1016/S0090-4295(02)01536-4

15. Zagouri F, Papaefthimiou M, Chalazonitis AN, et al. Prostate cancer with metastasis to the omentum and massive ascites: a rare manifestation of a common disease. Onkologie 2009;32:758-61. http:// dx.doi.org/10.1159/000255336. Epub 2009 Nov 20.

16. Falzarano SM, Magi-Galluzzi C. Prostate cancer staging and grading at radical prostatectomy over time. Adv Anat Pathol 2011;18:159-64. http://dx.doi.org/10.1097/PaP.0b013e31820cb506

17. Galper SL, Chen MH, Catalona WJ, et al. Evidence to Support a Continued Stage Migration and Decrease in Prostate Cancer Specific Mortality. J Urol 2006;175:907-12. http://dx.doi.org/10.1016/S0022$5347(05) 00419-2$

18. Derweesh IH, Kupelian PA, Zippe C, et al. Continuing trends in pathological stage migration in radical prostatectomy specimens. Urol Oncol 2004;22:300-6. http://dx.doi.org/10.1016/j.urolonc.2003.11.011

19. Gallina A, Chun FKH, Suardi N, et al. Comparison of stage migration patterns between Europe and the USA: an analysis of 11350 men treated with radical prostatectomy for prostate cancer. BJU Int 2008;101:1513-8. http://dx.doi.org/10.1111/i.1464-410X.2008.07519.x

20. Saif MW. Malignant Ascites Associated with Carcinoma of the Prostate. J Appl Res 2005;5:305-11

Correspondence: Dr. Ifeanyi Ani, Department of Urology, University Hospitals Case Medical Center, 11106 Euclid Ave, Cleveland, OH 44106; ifeanyichukwuani@uhhospitals.org 